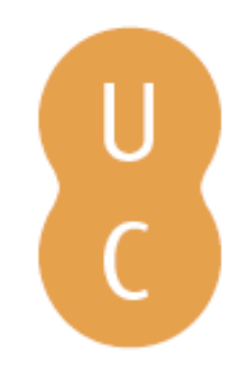

\title{
pommalina
}

\section{Evolução dos tratos de sistemas continentais neocretáceos da porção sudeste da plataforma sul-americana}

\author{
Autor(es): $\quad$ Batezelli, A. \\ Publicado por: Imprensa da Universidade de Coimbra \\ URL \\ persistente: URI:http://hdl.handle.net/10316.2/31399 \\ DOI: $\quad$ DOI:http://dx.doi.org/10.14195/978-989-26-0534-0_11 \\ Accessed : $\quad$ 26-Apr-2023 06:25:28
}

A navegação consulta e descarregamento dos títulos inseridos nas Bibliotecas Digitais UC Digitalis, UC Pombalina e UC Impactum, pressupõem a aceitação plena e sem reservas dos Termos e Condições de Uso destas Bibliotecas Digitais, disponíveis em https://digitalis.uc.pt/pt-pt/termos.

Conforme exposto nos referidos Termos e Condições de Uso, o descarregamento de títulos de acesso restrito requer uma licença válida de autorização devendo o utilizador aceder ao(s) documento(s) a partir de um endereço de IP da instituição detentora da supramencionada licença.

Ao utilizador é apenas permitido o descarregamento para uso pessoal, pelo que o emprego do(s) título(s) descarregado(s) para outro fim, designadamente comercial, carece de autorização do respetivo autor ou editor da obra.

Na medida em que todas as obras da UC Digitalis se encontram protegidas pelo Código do Direito de Autor e Direitos Conexos e demais legislação aplicável, toda a cópia, parcial ou total, deste documento, nos casos em que é legalmente admitida, deverá conter ou fazer-se acompanhar por este aviso.

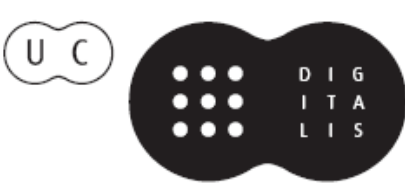



11

\title{
EVOLUÇÃO DOS TRATOS DE SISTEMAS CONTINENTTAIS NEOCRETÁCEOS DA PORÇÃO SUDESTE DA PLATAFORMA SUL-AMERICANA
}

\author{
NEOCRETACEOUS CONTINENTAL SYSTEMS \\ TRACTS EVOLUTION OF SOUTHEAST \\ SOUTH AMERICAN PLATE
}

A. Batezelli ${ }^{1}$

Resumo - Com o término das manifestaçôes vulcânicas eocretáceas (133 Ma), a porção Sudeste da Placa Sul-americana passou por um processo de reestruturação tectônica gerando bacias que abrigaram sequências sedimentares continentais. Os eventos tectônicos responsáveis pelo acúmulo dessas sequências podem ser divididos em duas fases principais. A primeira fase está relacionada à formação da Bacia Caiuá, enquanto que a segunda, é marcada pela Bacia Bauru. Análises sedimentológicas e estratigráficas mostraram que a Bacia Caiuá (Eocretáceo) foi caracterizada por uma depressão cujo depocentro estaria localizado na porção mais ao sul da placa Sulamericana, no estado do Paraná. Nessa época, o clima era árido, atestado por uma sedimentação eólica. A Bacia Bauru, gerada no Neocretáceo, apresenta depocentro situado entre o oeste de São Paulo e sudoeste de Minas Gerais, abrigando depósitos lacustres rasos e aluviais de clima árido a semi-árido, com características sedimentológicas e paleopedológicas sugestivas de condiçôes climáticas mais úmidas. Através da análise estratigráfica, baseada em poços e afloramentos, associados aos estudos petrográficos, foram identificadas duas superfícies que registram importantes mudanças nas condições tectônicas e paleoambientais da Bacia Bauru. A primeira, relacionada com a origem da Bacia Bauru no Cretáceo Superior, marca a reestruturação tectônica pela qual a porção sudeste da Placa Sul-Americana foi submetida. Esta superfície separa o trato de sistemas desértico eocretáceo do trato de sistemas lacustre/aluvial neocretáceo. A segunda superfície, no topo da sequência lacustre, registra mudanças nas condiçôes tectonossedimentares, bem como, paleoambientais e paleoclimáticas.

\footnotetext{
1 Departamento de Geologia e Recursos Naturais (DGRN) do Instituto de Geociências da Universidade Estadual de Campinas - DGRN - IG -UNICAMP. Rua João Pandiá Calógeras, n. 51 - Barão Geraldo Campinas - SP, Brasil. Fax (19) 3289-1562 - CEP: 13083-870 - abatezelli@ige.unicamp.br
} 
Palavras-Chave - Placa Sul-americana; Tratos de sistemas continentais; Fácies; paleossolos; Condiçóes paleoclimáticas

Abstract - With the end of the Eocretaceous volcanic manifestations (133 Ma), the southeastern portion of the South American Plate underwent tectonic restructuring, which generated basins that encompassed continental sedimentary sequences. The tectonic events responsible for the accumulation of such sequences can be divided in two main phases. The first phase is related to the Eocretaceous thermal subsidence, resulting in the formation of the Caiua basin. The second phase, during which the Bauru Basin was originated, was related to the Neocretaceous uplifts in southwestern Minas Gerais and southern Goiás, related to the magmatic activities. The analyses showed that the Caiua Basin is characterized by a depression whose depocenter was located to the south. At that time, the climate was arid, as attested by the aeolian sedimentation. The Bauru Basin, generated in the Neocretaceous and with depocenter located to the northern, encompasses playa-lake and alluvial deposits of arid to semi-arid climate, with sedimentological and paleopedological characteristics suggestive of more humid climatic conditions. By means of stratigraphic analysis based on wells and outcrops and aided by petrographic studies, two surfaces were identified that record important changes in the Bauru Basin tectonic and paleoenvironmental conditions. The first, related to the origin of the Bauru Basin, marks the tectonic restructuring that affected the southeastern portion of the South American Plate. It separates the Eocretaceous desertic system tract from the Neocretaceous lacustrine/playalakelalluvial system tract. The second surface at the top of the lacustrine/playa-lake sequence records changes in the tectono-sedimentary, as well as paleoenvironmental and paleoclimatic conditions.

Keywords - South American Plate; Continental system tracts; Facies; paleosols; Paleoclimatic conditions

\section{1 - Introdução}

Entre os eventos mesozóicos que afetaram a Plataforma Sul-Americana, um dos mais expressivos foi o magmatismo básico toleí́tico ocorrido entre 137,4 a 128,7 Ma (TURNER et al., 1994) e que foi responsável pela gênese de uma das maiores Províncias Magmáticas continentais do mundo (Continental Flood Basalts) (SAUNDERS et al., 1992). Com o término das atividades vulcânicas eocretáceas, a porção meridional da placa Sul-Americana sofreu um processo de subsidência termal, culminando com o desenvolvimento de bacias interiores, com destaque para a Bacia Caiuá (Eocretáceo).

No Neocretáceo, soerguimentos relacionados à passagem da Pluma Mantélica de Trindade na porção centro-oeste da Placa Sul-Americana (GIBSON et al., 1995), reestruturam a paisagem, dando origem a uma depressão bacinal que se estende por aproximadamente $330.000 \mathrm{~km}^{2}$, denominada Bacia Bauru (Fig. 1). Seu embasamento é constituído, em parte, por basaltos da Formação Serra Geral e arenitos eólicos do Grupo Caiuá, ambos de idade Eocretácea. 
A integração de dados estratigráficos e faciológicos permitiu definir a arquitetura estratigráfica da Bacia Bauru, subsidiando um modelo de evoluçáo de sequências continentais, onde se contemplam mudanças na taxa de sedimentação e no espaço de acomodação dos sedimentos ocorridos em dois períodos marcantes. O primeiro período está relacionado com a fase inicial de implantação da Bacia Bauru, no Campaniano inferior, representado por uma superfície discordante que limita os grupos Caiuá (Eocretáceo) e Bauru (Neocretáceo). O segundo período ocorre no intervalo Campaniano - Maastrichtiano e é marcado pela mudança no estilo deposicional ocorrido na bacia.

Análises petrográficas associadas a informaçóes de isótopos estáveis de $\delta \mathrm{C}^{13} \mathrm{e}$ de $\delta \mathrm{O}^{18}$ possibilitaram identificar processos deposicionais e pedogenéticos, com importantes consideraçôes sobre as condiçôes paleoclimáticas ocorridas nesse período. Os dados levantados permitiram definir dois ciclos tectonossedimentares com condiçóes paleoambientais específicas na Bacia Bauru, caracterizados segundo terminologia de sequências continentais proposta por MARTINSEN et al. (1999).

Os depósitos lacustres, tipo playa-lakes, e fluviais psefítico/pelíticos das formações Araçatuba e Adamantina, representam o estágio inicial de preenchimento da bacia e são referidos como Trato de Sistemas de Alta Taxa de Acomodação. O ciclo seguinte é marcado por uma sequência progradacional, iniciada por depósitos fluviais entrelaçados de baixa sinuosidade (formaçóes Adamantina e Uberaba), sucedidos por depósitos aluviais dominados por rios entrelaçados com retrabalhamento eólico (Formação Marília), correspondendo a um Trato de Sistemas de Baixa Taxa de Acomodação.

\section{2 - Área de estudo e método de análise}

A área de estudo está situada na porção sudeste da Placa Sul-Americana, correspondendo à faixa de afloramentos dos grupos Caiuá e Bauru, região sul e sudeste do Brasil, nos estados do Paraná, São Paulo, Minas Gerais, Goiás e Mato Grosso do Sul, situando-se entre os paralelos $23^{\circ}$ e $18^{\circ}$ de latitude sul e os meridianos $49^{\circ}$ e $55^{\circ}$ de longitude oeste (Fig. 1).

O método de estudo empregado na pesquisa baseou-se principalmente na análise da arquitetura estratigráfica da bacia através de informaçóes de poços e afloramentos (descriçōes litológicas, perfis radioativos, análise de fácies, petrografia, isótopos estáveis e paleontologia).

\section{1 - Bacia Caiuá}

Denominada por FULFARO et al. (1999), essa bacia foi estudada por FERNANDES \& COIMBRA (2000) e abriga rochas do Grupo Caiuá (formações Goio Erê, Rio Paraná e Santo Anastácio), com afloramentos no oeste dos estados do Paraná e São Paulo, e leste do Mato Grosso do Sul (Fig. 1). Assenta discordantemente sobre os basaltos da Formação Serra Geral, com espessuras que podem atingir até 280 metros na região de Altônia (PR). 


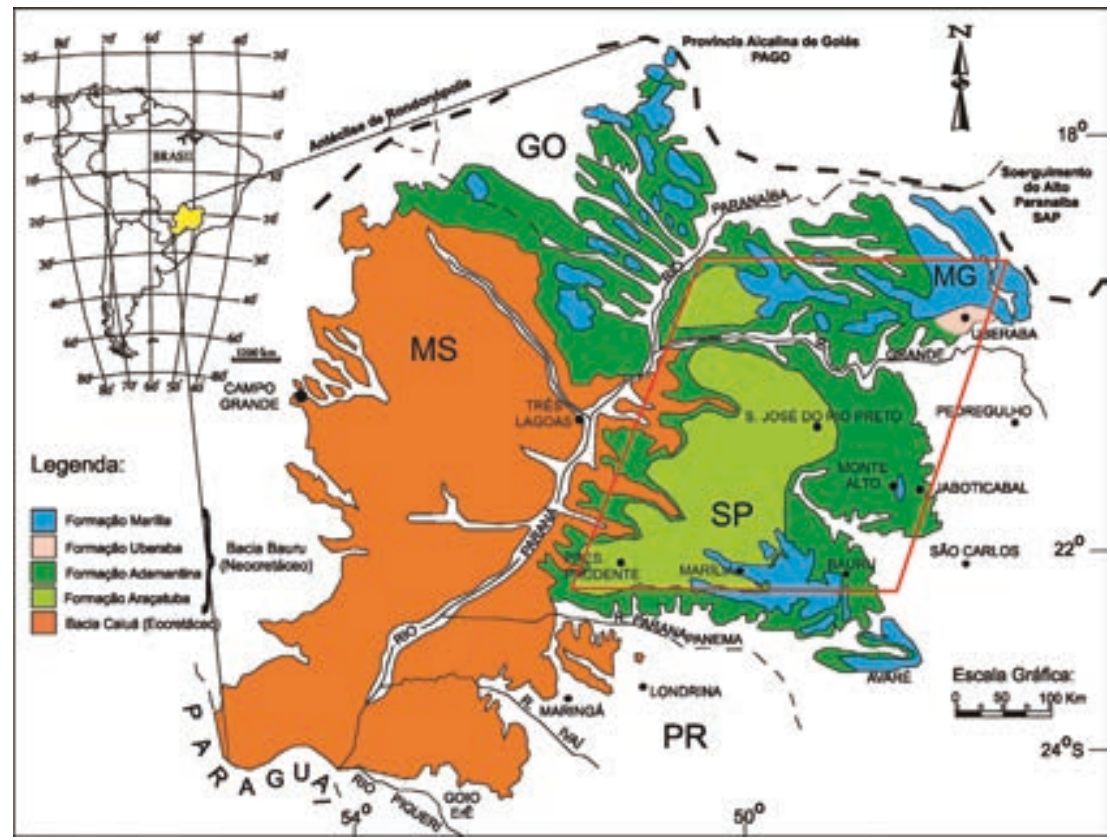

Fig. 1 - Mapa de distribuição da sequência cretácea. Área de estudo delineada pelo polígono vermelho.

Suas unidades são constituídas basicamente por arenitos muito finos a finos, quartzosos, bem selecionados, de coloraçáo marrom-avermelhada a arroxeadas, com estratificação cruzadas de médio a grande porte, com camadas frontais da ordem de 10 metros de altura e com baixa inclinação. Apresentam alta maturidade textural e mineralógica, com grãos exibindo brilho fosco e películas de óxido de ferro. As estratificações cruzadas são formadas pela alternância de bandas de espessura milimétrica a centimétrica de boa seleção interna e caráter bimodal.

Adicionalmente ocorrem arenitos finos a médios, arroxeados, em estratos tabulares com estratificaçóes cruzadas de médio porte, intercalados com arenitos maciços ou com estratificaçôes planoparalelas, onduladas de adesão e onduladas cavalgantes. Nessa fácies é frequente o revestimento dos grãos de quartzo por argilas autigênicas (esmectitas), transformadas em caulinita por processos intempéricos. A cimentação por carbonato é comum, ocorrendo sob a forma de crostas e nódulos. Subordinadamente ocorre na base dessa fácies arenitos conglomeráticos sustentados por matriz areno-lamítica com clastos de basalto, ágata, argila e carbonato.

Em muitas áreas da bacia ocorre, no topo do Grupo Caiuá, um arenito fino, bem selecionado, maciço e com feições de dissolução, com espessura que varia de alguns metros até 100 metros, conhecido formalmente como Formação Santo Anastácio.

BATEZELLI et al. (2003), através de dados de campo, concluíram que a Formação Santo Anastácio corresponde a um espesso paleossolo (Geossolo Santo Anastácio) gerado sobre os depósitos eólicos da Formação Rio Paraná (topo do Grupo Caiuá).

Segundo FERNANDES \& COIMBRA (2000), as características faciológicas dessa unidade indicam que seu contexto deposicional compreende construçôes de dunas eólicas de grande porte (draas), complexos de dunas de cristas sinuosas, amalgamadas, de 
região central de Mar de Areia (Sand Sea). Nas porções periféricas desse Mar de Areia desenvolver-se-iam dunas de tamanho médio, sujeitas às influências da variação do nível freático raso e possíveis enxurradas efêmeras.

\section{2 - Bacia Bauru}

Registro de sedimentação continental, o Grupo Bauru, unidade litoestratigráfica que compóe a bacia homônima, assenta discordantemente sobre os depósitos eólicos do Grupo Caiuá, e é constituído por rochas areno-lamíticas na base (Formação Araçatuba), gradando para arenitos e conglomerados no topo (formaçôes Adamantina / Uberaba e Marília) (Fig. 2), constituindo tratos de sistemas lacustre/aluvial (BATEZELLI et al., 2003). Suas fácies indicam processos sedimentares subaquosos associados à decantação em corpos d'água rasos com constante exposição subaérea (playa-lakes), além de fluxos tracionais e combinados relacionados a correntes fluviais, ondas e correntes de turbidez, com retrabalhamento eólico, sob condiçôes climáticas semi-áridas a áridas.

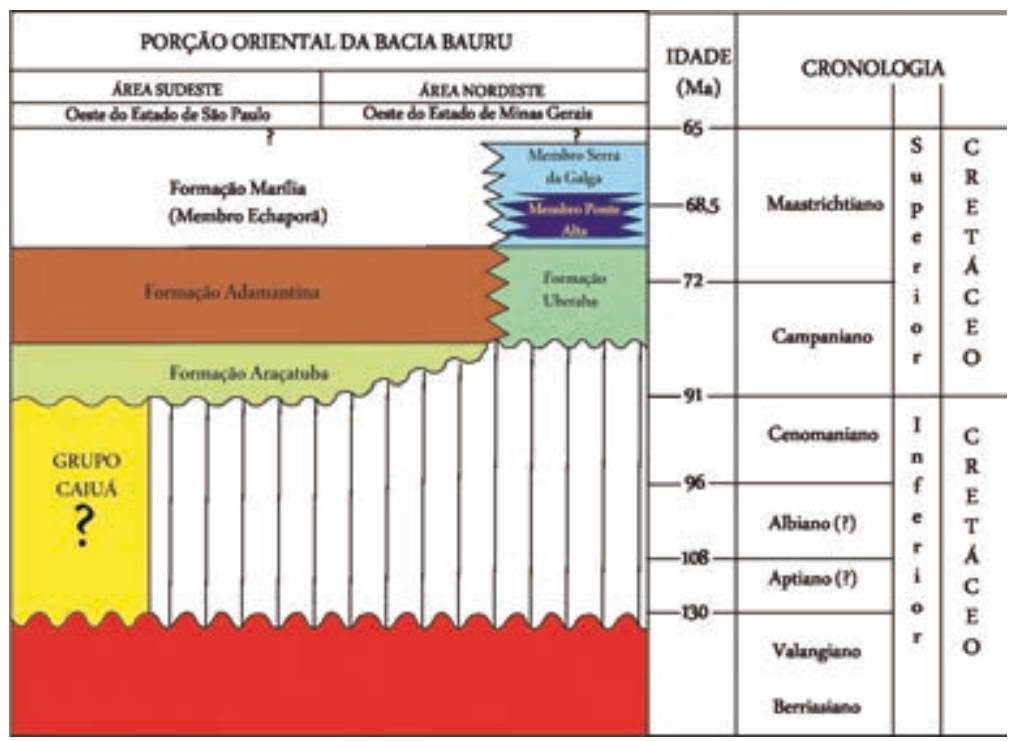

Fig. 2 - Carta cronoestratigráfica da sequência suprabasáltica do sudeste brasileiro.

O limite entre os grupos Bauru e Caiuá é marcado por uma superfície de descontinuidade que separa os arenitos do Geossolo Santo Anastácio, dos siltitos esverdeados da Formação Araçatuba, que pode ser encontrada em afloramentos e em poços.

A Formação Araçatuba, unidade basal do Grupo Bauru, é constituída por arenitos muito finos, siltosos e siltitos arenosos, coloração cinza-esverdeada a avermelhada, apresentando gradação normal, geralmente estratificaçóes plano-paralelas. Por vezes, os arenitos se apresentam maciços, com marcas de raízes, gretas de ressecamento, e às vezes, estratificaçôes cruzadas acanaladas de pequeno a médio porte (até $150 \mathrm{~cm}$ de comprimento). 
Característica marcante dessa unidade são as muitas ocorrências de moldes romboédricos de cristais de calcita, descritos por BATEZELLI et al. (2003).

O contato basal da Formação Araçatuba é discordante tanto em relação aos basaltos da Formação Serra Geral, quanto aos arenitos do Grupo Caiuá (Formação Santo Anastácio). Seu contato superior e lateral se dá de forma gradacional e interdigitado, respectivamente, com os arenitos finos a médios avermelhados da Formação Adamantina (Formação Vale do Rio do Peixe, segundo FERNANDES \& COIMBRA, 2000).

As formaçóes Adamantina e Uberaba são constituídas por arenitos vermelhos e esverdeados, lamíticos e, subordinadamente, conglomerados, com intercalaçôes lamíticas, constituídos por grãos arredondados a sub arredondados de quartzo e hematita, com seleção moderada a boa. A geometria dos corpos, textura fina e estruturas sedimentares presentes nessa unidade indicam deposição por fluxos fluviais com desenvolvimento de planície lamítica. Campo de dunas eólicas baixas, tipo lençóis de areia, adjacentes a esses depósitos fluviais interagiam com os mesmos em períodos de seca, preenchendo cortes de canais abandonados.

A Formação Marília, unidade de topo da Bacia Bauru é constituída por arenitos e conglomerados muito cimentados por $\mathrm{CaCO}_{3}$, geralmente maciços, às vezes com estratificaçóes cruzadas de pequeno a médio porte (até 3 metros de foresets). As fácies arenosas e conglomeráticas se organizam em canais, barras lenticulares, macroformas de acréscimo lateral e à jusante.

Do ponto de vista litoestratigráfico, essa unidade é dividida em 3 membros, diferenciados através das litofácies e do conteúdo carbonático (membros Ponte Alta, Serra da Galga e Echaporã) A característica mais marcante da Formação Marília é a grande ocorrência de níveis de paleossolos que se alternam aos depósitos arenosos e conglomeráticos, perfazendo até $70 \%$ das seçôes descritas em algumas áreas.

3 - Resultados e discussóes sobre o arcabouço tectono-estratigráfico e evolução dos tratos de sistemas

A partir da análise de dados de subsuperfície foram confeccionadas seções estratigráficas que recortam toda a área de ocorrência das unidades do Grupo Bauru. A Fig. 3 apresenta a seção Uberlândia (MG) - Teodoro Sampaio (SP), de direção NE, e a seção Colina (SP) - Santana da Ponte Pensa (SP), de direção E-W. Para a elaboração das seçóes foi utilizado como marco estratigráfico o topo da Formação Araçatuba (lacustre).

A seção de direção aproximada NE-SW mostra simetria dos depósitos lacustres, quando comparada com a seção leste-oeste (Fig. 3B), cuja arquitetura mostra perfil assimétrico, com espessamento das fácies lacustres para oeste.

Do ponto de vista estratigráfico, as características do limite entre as unidades Caiuá e Bauru, encontradas no topo da Formação Santo Anastácio, são semelhantes àquelas que definem a Super-Superfícies de KOCUREK (1988). Essas superfícies truncam, de forma abrupta, depósitos de dunas, draas e interdunas, encerrando diferentes conjuntos litológicos abaixo e acima, sugerindo a parada na deposição do Erg (Deserto Caiuá).

O Geossolo Santo Anastácio marca a parada na sedimentação e a atuação de processos pedogenéticos. Após um período de tempo sem sedimentação, a bacia sofreu novo processo de subsidência flexural associado à elevação de suas bordas norte e nordeste (SAP 
e PAGO), gerando espaço de acomodação. Esse evento ficou marcado e representado no registro geológico da bacia através de uma superfície com grande expressão regional sobre a qual repousa os depósitos fluviais e de playa-lake da Formação Araçatuba. A reestruturação tectônica fica evidente nas seçóes estratigráficas da (Fig. 3).

As características observadas para o topo da Formação Santo Anastácio, no limite entre os grupos Caiuá e Bauru, demonstram que a preservação da Super-superfície ocorreu devido à estabilizaçáo do paleossolo por processos paleopedogenéticos e desenvolvimento de vegetaçáo, tornando-a resistente à erosão. Associado a isso, a subsidência da bacia, posicionando os depósitos abaixo do nível de base estratigráfico, também contribuíram para sua preservação (Fig. 3).

Cessado o ciclo de sedimentação Caiuá, essa região passou a ter um balanço sedimentar neutro, formando uma superfície do tipo reliquiar estabilizada. Dessa forma, a superfície resultante pode ser considerada uma superfície de bypass ou erosão, segundo a concepção de KOCUREK \& HAVHOLM (1993).

A reestruturação tectônica, responsável por essa grande discordância entre os grupos Caiuá e Bauru, provavelmente se deu no Campaniano Superior, após o período de maior atividade magmática ocorrida na borda norte/nordeste da Bacia Bauru, que compreende o intervalo Coniaciano e Campaniano Médio (Fig. 2).

Nesse novo contexto, a regiáo foi palco de um evento sedimentar marcado por depósitos arenosos de origem fluvial/lacustre (Formaçáo Araçatuba) (Fig. 3), na base. Com o aumento na taxa de subsidência, a depressão tornou-se maior e adquiriu caráter de uma bacia endorreica tipo playa-lake.

A evolução de um trato de sistema de alta taxa de acomodação para um trato de sistema de baixa taxa de acomodação (high/low-accommodation system tract), conforme terminologia proposta por MARTINSEN et al. (1999), é evidenciada pelo empilhamento progradacional do sistema aluvial sobre o sistema lacustre.

Dessa forma, a fase inicial da Bacia Bauru seria marcada pela implantação e expansão de playa-lakes (trato de sistema de alta taxa de acomodaçáo), seguido de uma fase de contração, marcado pela progradação dos depósitos aluviais dominados por rios entrelaçados de baixa sinuosidade (trato de sistema de baixa taxa de acomodaçáo).

Do ponto de vista paleoclimático, admite-se que o ciclo sedimentar que deu origem a sequência Bauru sofreu variaçóes nas condiçóes de umidade, sendo que em direção ao topo, ocorre um aumento de feiçóes indicadoras de clima árido/semiárido (calcretes e paleossolos com Paligorskita).

Dados de isótopos estáveis de carbono e oxigênio em rochas carbonáticas e carapaças de ostracodes do Grupo Bauru, embora restritos a alguns pontos da bacia (SUGUIO, 1973; SUGUIO et al., 1975; SUGUIO et al., 1980; DIAS-BRITO et al., 2001) e sem um controle estratigráfico preciso, permitem tecer algumas considerações sobre as condiçóes paleoambientais e paleoecológicas da sequência neocretácea (GOBBO-RODRIGUES, 2001).

A Fig. 4 mostra tendência de correlaçáo positiva entre composiçóes isotópicas de oxigênio e carbono de amostras de rochas carbonáticas, tanto do topo como da base da Formação Marília. Os dados relativos às amostras das formaçôes Araçatuba e Adamantina são mais dispersos, contudo revelam tendência semelhante.

Os maiores valores de $\delta^{18} \mathrm{O}$ observados tanto na base da Formaçáo Marília como na Formação Araçatuba podem indicar precipitação carbonática a partir de águas mais salinas e/ou que sofreram taxa maior de evaporação. 


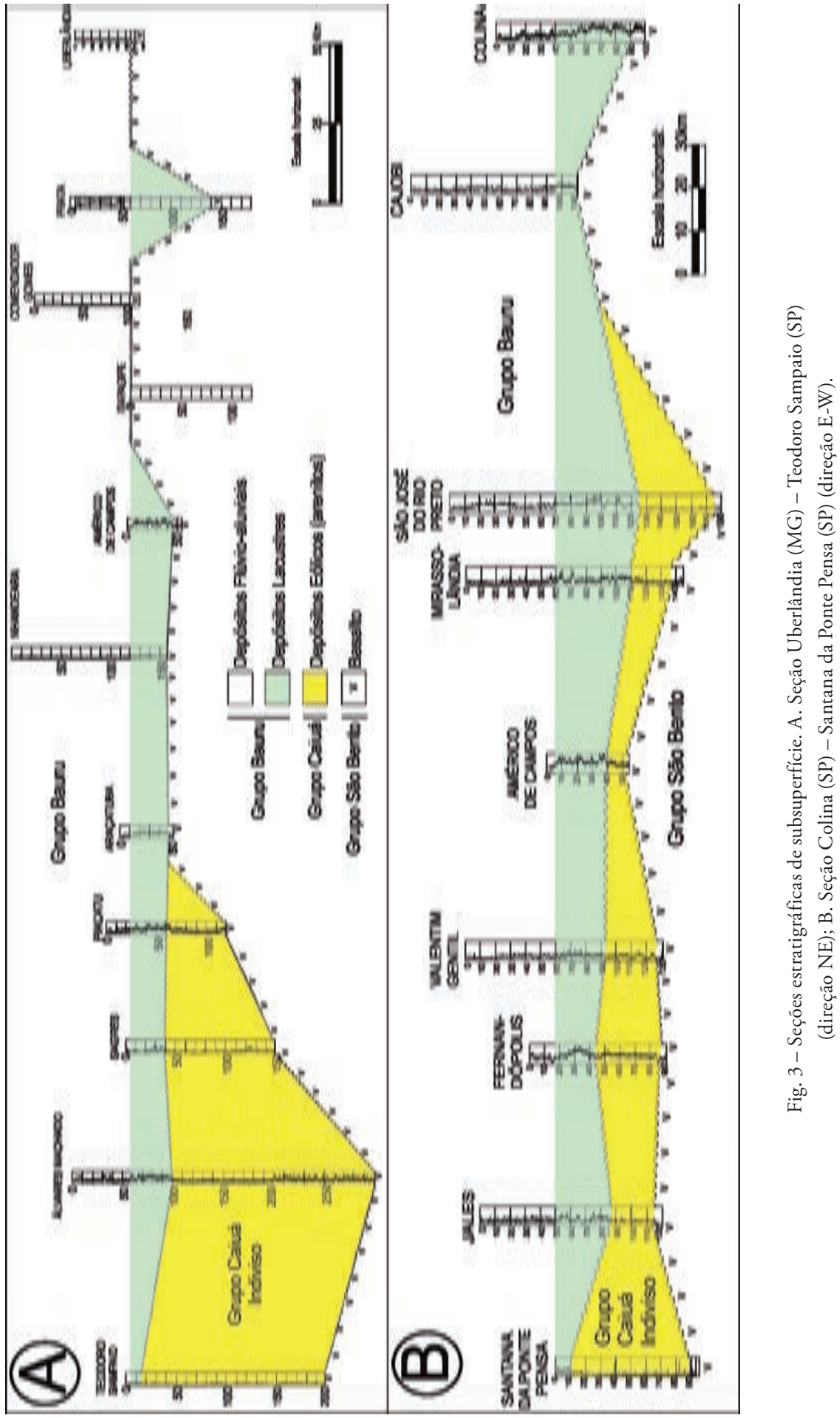


Valores mais elevados de $\delta^{13} \mathrm{C}$, sobretudo da Formação Araçatuba, podem indicar que entre os ciclos sedimentares lacustre e aluvial, houve sensível aumento no potencial de oxidação da bacia, que pode estar relacionado a condiçóes climáticas mais quentes, com alta taxa de evaporação.

\section{4 - Conclusôes}

A geração das superfícies limítrofes e os estilos deposicionais distintos de cada trato são interpretados devido às variaçóes do nível de base estratigráfico, expresso pela relação entre espaço de acomodação (A) e suprimento (S). Os limites de sequências são gerados durante as fases de abrupta reduçáo de espaço de acomodação, quando a razão A/S passa a ser zero (0) ou negativa, condiçóes que provocam a ocorrência de by-pass sedimentar e a formação de extensivas superfícies de erosão, conforme observado no limite Caiuá / Bauru.

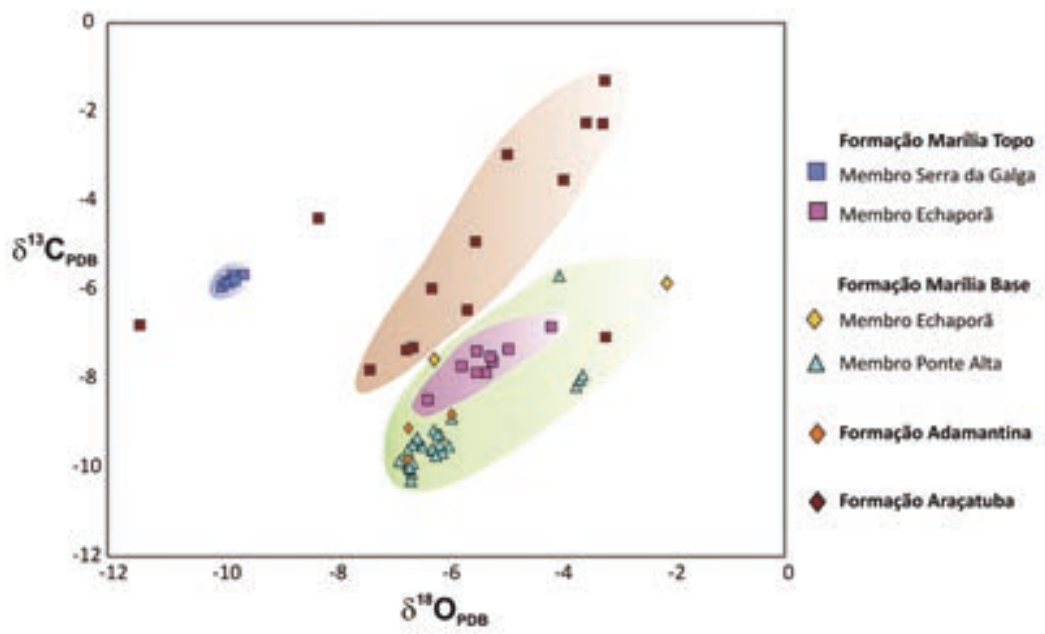

Fig. 4 - Composição isotópica de oxigênio vs. carbono de rochas carbonáticas, carapaças de ostracodes e girogonites de carófitos do Grupo Bauru (Fonte dos dados: SUGUIO, 1973; SUGUIO et al., 1975; SUGUIO et al., 1980; DIAS-BRITO et al., 2001).

Nesse sentido, o trato de baixa taxa de acomodação é representado pelos depósitos lateralmente contínuos de canais fluviais amalgamados (sheets), multiepisódicos e multilaterais, da base da Formação Araçatuba, gerados quando a razão A/S é positiva, mas inferior à unidade, resultando no preenchimento de todo o espaço disponível e eventual by-pass sedimentar. Quando a razão A/S aumenta abruptamente, atingindo a unidade, ocorre o desenvolvimento de depósitos finos, regionalmente expressivos (superfícies de expansão) que delimitam, no topo, o trato de baixa taxa de acomodação. Na área de estudo o aumento da razão A/S foi muito elevada, provavelmente superior a 1 , o que fez com que o espaço disponível fosse maior que o aporte sedimentar. Essa feiçáo é representada pelos depósitos lacustres do tipo playa-lakes da Formação Araçatuba, marcando a fase inicial de um trato de alta taxa de acomodação (Fig. 5). 


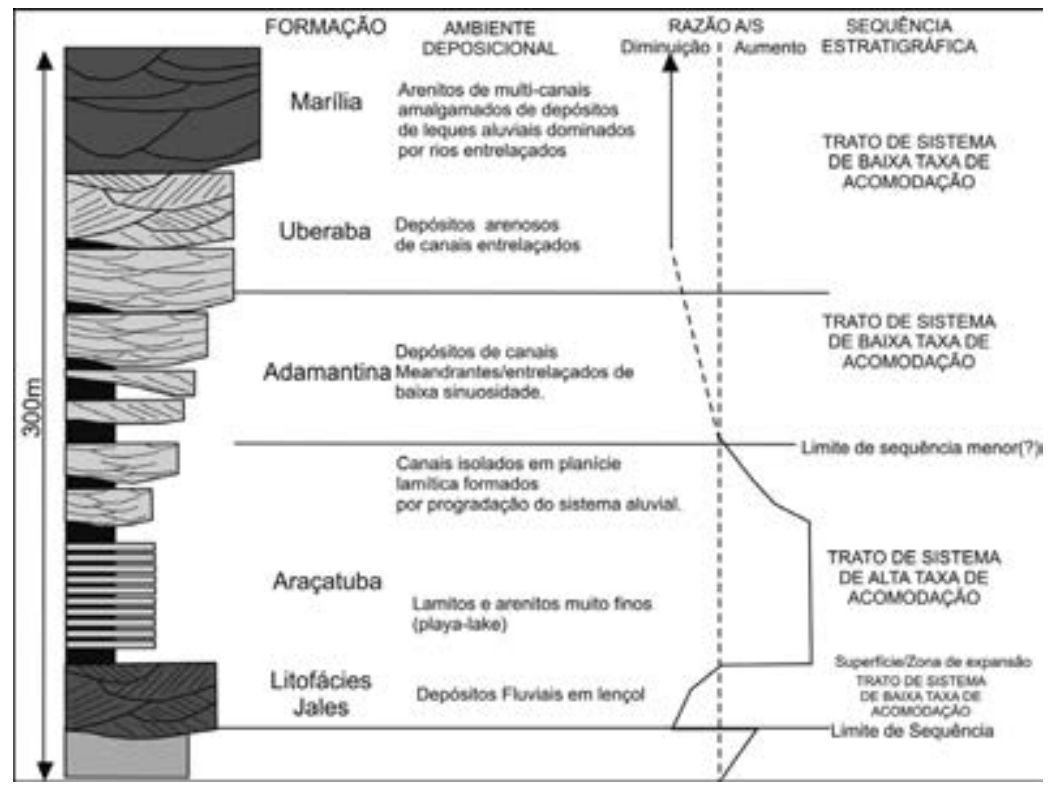

Fig. 5 - Modelo de evolução da sequência neocretácea do sudeste brasileiro.

O subsequente aumento no aporte sedimentar causado pelos constantes pulsos de elevação das bordas da Bacia Bauru a norte (Província Alcalina de Goiás) e a nordeste (Soerguimento do Alto Paranaíba), associado à progressiva diminuição do espaço de acomodação, fez com que depósitos fluviais meandrantes e entrelaçados colmatassem progressivamente o ambiente lacustre (playa-lake), ainda nesta fase (formaçóes Adamantina e Uberaba) (Fig. 5).

A estabilização do nível de base estratigráfico ocorreu com o aumento do espaço de acomodação subaérea, culminando com a acumulação de depósitos aluviais distribuídos em um trato de alta taxa de acomodação e representados pela Formação Marília (Fig. 5).

As feições sedimentares e petrográficas descritas, associadas aos dados isotópicos, indicam que a área de estudo foi palco de variaçóes paleoclimáticas significativas, sobretudo, nas condiçóes de umidade.

A primeira mudança é observada no contato entre os grupos Caiuá e Bauru, onde os depósitos eólicos eocretáceos são sobrepostos por depósitos fluvio-lacustres, após um período de longa exposição e atuação de processos pedogenéticos (Geossolo Santo Anastácio). E a segunda está registrada na transiçáo entre os tratos de sistemas de alta taxa de acomodação e baixa taxa de acomodação, representada pela variação no estilo deposicional, que passa para depósitos aluviais dominados por rios efêmeros, com longos períodos de exposição e atuação de processos pedogenéticos.

Agradecimentos - $\mathrm{O}$ autor expressa seus agradecimentos à Professora Lena Virgínia Soares Monteiro pelas discussóes sobre os dados isotópicos, e à Fundação de Amparo à Pesquisa do Estado de Sáo Paulo (FAPESP) pelo apoio e financiamento do projeto 
FAPESP 2010/19787-1 Correlação Estratigráfica e Paleogeografia do Cretáceo Superior nas Bacias Bauru, Sanfranciscana e dos Parecis.

\section{Referências Bibliográficas}

BATEZElli, A., SAAD, A. R., ETCHEBEHERE, M. L. DE C., PERINOTTO, J. A. DE J. \& FULFARO, V. J. (2003) - Análise Estratigráfica Aplicada À Formação Araçatuba (Grupo Bauru - Ks) No Centro-Oeste do Estado de São Paulo. Revista Geociências, n.o Especial, 22, p. 5-19.

DIAS-BRITO, D., MUSACCHIO, E. A., CASTRO, J. C., MARANHÃO, M. S. A. S., SUÁREZ, J. M. \& RODRIGUES, R., (2001) - Grupo Bauru: uma unidade continental Cretácea no Brasil - concepçóes baseadas em dados micropaleontológicos, isotópicos e estratigráficos - Revue Paléobiologic, Genève, 20, p. 245-304.

FERNANDES, L. A. \& COIMBRA, A. M., (2000) - Revisão Estratigráfica da Parte Oriental da Bacia Bauru (Neocretáceo) - Rev. Bras. de Geoc., 30, p. 717-728.

Fulfaro, V. J., ETCHeBehere, M. L. D. C., PERinOtTO, J. A. J. \& SAAD, A. R. (1999) - Bacia Caiuá: Uma nova Bacia Cretácea na Bacia do Paraná. In: Simpósio Sobre o Cretáceo do Brasil, 5, e Simposio Sobre el Cretácico de América del Sur, 1, Serra Negra, Boletim, p. 439-442.

GIBSON, S. A., THOMPSON, R. N., LEONARDOS, O. H., DICKIN, A. P. \& MITCHELL, J. G., (1995) The Late Cretaceous Impact of the Trindade Mantle Plume: Evidence From Large Volume, Mafic, Potassic Magmatism in SE Brazil. Journal of Petrology, 36, p. 189-229.

GOBBO-RODRIGUES, S. R. (2001) - Carófitas e Ostrácodes do Grupo Bauru. Dissertação de Mestrado, Instituto de Geociências e Ciências Exatas, Universidade Estadual Paulista, Rio Claro (SP), 137 p.

KOCUREK, G. (1988) - First-order and super bounding surfaces in eolian sequences - bounding surfaces revisited. In: Kocurek, G. (eds.). Late Paleozoic and Mesozoic Eolian Deposits of the Western Interior of the United States. (Sed. Geology Spec. Publi.). Sed. Geol., 56, p. 193-206.

KOCUREK, G. \& HAVHOLM, K. G. (1993) - Eolian sequence stratigraphy - A conceptual framework. In: Weimer, P. \& Posamentier, h. W. (eds.). Siliciclastic Sequence Stratigraphy. Tulsa, AAPG Memoir \# 58, p. 393-409.

MARTINSEN, O. J., RYSETH, A., HELlAND-HANSEN, W., FLESHE, H., TORKILDSEN, G. \& IDILL, S. (1999) - Stratigraphic Base Level and Fluvial Architecture: Ericson Sandstone (Campanian), Rocky Springs Uplift, SW Wyoming, USA. Sedimentology, 46, p. 235-259.

SANTUCCI, R. M. \& BERTINI, R. J., (2001) - Distribuição Paleogeográfica e Biocronológica dos Titanossauros (Saurishia, Sauropoda) do Grupo Bauru, Cretáceo Superior do Sudeste Brasileiro. Rev. Bras. Geoc., 31, p. 307-315.

SAUNDERS, A. D., STOREY, M., KENT, R. W. \& NORRY, M. J. (1992) - Consequences of plume-lithosphere interactions. In: Storey, M., Alabaster, A., Pankhurst, R.J. (eds.). Magmatism and the Causes of Continental Break-up. Bath. Geological Society of London, Special Publication, 68, p. 41-60.

SUGUIO, K. (1973) - Formação Bauru. Calcários e sedimentos detríticos associados. Unpublished Livre Docência Thesis, Universidade de São Paulo, 236 p.

SUGUIO, K., BERENHOLC, M. \& SALATI, E. (1975) - Composição Química e Isotópica dos Calcários e Ambiente de Sedimentação da Formação Bauru. Boletim do Instituto de Geociências, USP, 6, p. 55-75.

SUGUIO, K., BARCELOS, J. H. \& MATSUI, E. (1980) - Significados paleoclimáticos e paleoambientais das rochas calcárias da Formação Caatinga (BA) e do Grupo Bauru (MG/SP). In: CONGRESSO BRASILEIRO DE GEOLOGIA, 31, 1980, Camboriú. Anais... Camboriú: Sociedade Brasileira de Geologia, 1, p. 607-617.

TURNER, S., REGELONS, M., KELLEY, S., HAWKESWORTH, C. \& MANTOVANI, M. S. M. (1994) - Magmatism and continental break-up in the South Atlantic: high precision geochronology. Earth and Planetary Science Letters, 121, p. 333-348. 